This is an author-created, un-copyedited version of an article accepted for publication/published in Smart Materials and Structures, 24 (2015) 065025 (10pp)

IOP Publishing Ltd is not responsible for any errors or omissions in this version of the manuscript or any version derived from it. The Version of Record is available online at doi:10.1088/0964-

\title{
Thermal and damping behaviour of magnetic shape memory alloy composites
}

\author{
Susanne Glock and Véronique Michaud \\ Laboratoire de Technologie des Composites et Polymères (LTC), Ecole \\ Polytechnique Fédérale de Lausanne (EPFL), Lausanne, 1015, Switzerland \\ E-mail: veronique.michaud@epfl.ch
}

\begin{abstract}
Single crystals of ferromagnetic shape memory alloys (MSMA) exhibit magnetic field and stress induced strains via energy dissipating twinning. Embedding single crystalline MSMA particles into a polymer matrix could thus produce composites with enhanced energy dissipation, suitable for damping applications. Composites of ferromagnetic, martensitic or austenitic Ni-Mn-Ga powders embedded in a standard epoxy matrix were produced by casting. The martensitic powder composites showed a crystal structure dependent damping behaviour that was more dissipative than that of austenitic powder or $\mathrm{Cu}-\mathrm{Ni}$ reference powder composites and than that of the pure matrix. The loss ratio also increased with increasing strain amplitude and decreasing frequency, respectively. Furthermore, Ni-Mn-Ga powder composites exhibited an increased damping behaviour at the martensite/austenite transformation temperature of the Ni-Mn-Ga particles in addition to that at the glass transition temperature of the epoxy matrix, creating possible synergetic effects.
\end{abstract}

\section{Introduction}

Ferromagnetic shape memory alloys like Ni-Mn-Ga show magnetic field induced strains of up to $10 \%$ at actuation frequencies of up to $2 \mathrm{kHz}$ and mechanical load induced strains of up to $20 \%$ [13]. These large deformations are caused by the motion of twin boundaries that exist only in the low temperature, martensitic phase and are thus not possible in the parent, austenitic phase of shape 
memory alloys. Since twinning is a dissipative effect, MSMAs are promising candidates for applications requiring damping. To guarantee, however, that mechanical load induced twinning results in a high dissipation rate, the twinning stress, which depends on the crystal structure and thus on the composition of the alloy, needs to be high. While $10 \mathrm{M}$ pseudo-tetragonal and $14 \mathrm{M}$ pseudoorthorhombic martensite exhibit twinning stresses as low as $0.1 \mathrm{MPa}$ [4], NM tetragonal martensite has a much higher twinning stress of typically 10-20 MPa [3].

Single crystals of Ni-Mn-Ga display the best properties but are very expensive to produce. Polycrystalline materials are brittle, grain boundaries increase the twinning stress and the presence of various grain orientations hinders twinning. Thus, a promising route to obtain structures suitable for damping applications is to produce MSMA composites with single crystalline powders [5-8] or bamboo-structured fibres [9] embedded in a polymer matrix.

In 2003, Feuchtwanger et al [5] proposed to investigate the behaviour of Ni-Mn-Ga composites, made to overcome the shortcomings of polycrystalline bulk Ni-Mn-Ga. They produced composite samples by adding $20 \mathrm{vol} \% \mathrm{Ni}-\mathrm{Mn}-\mathrm{Ga}$ particles, obtained by milling single crystals and having a size below $45 \mu \mathrm{m}$, to a PU matrix. To align the magnetic easy axes of the particles, the composites were cured under an applied magnetic field. Using these composite samples, they investigated the damping potential by measuring stress-strain curves. They observed an increased hysteresis and thus an increased energy loss compared to a pure PU sample as well as compared to a composite with Fe particles embedded in the same PU and attributed this to the motion of twin boundaries. Recently, they also investigated the energy absorption of such composites under impact, showing promising results [10]. Liang et al. [11] showed the effect of increasing volume fraction of $\mathrm{Ni}-\mathrm{Mn}$-Ga particles on the increase in damping for composites made with these particles and an epoxy matrix. Sun et al. [7] investigated the temperature dependency of the damping behaviour for Ni-Mn-Ga powder-epoxy matrix composites. They found a higher storage modulus and loss ratio $(\tan \delta)$ at room temperature than for the pure epoxy matrix caused by the reinforcement of the martensitic Ni-Mn-Ga particles. With increasing temperature, they detected a faster decreasing storage modulus as compared to the pure matrix. Furthermore, a two stage decrease of the storage modulus and a two stage increase of $\tan \delta$, respectively, were attributed to the reverse martensitic temperature and the glass transformation of the epoxy matrix. However, Lahelin et al. [8] found out that this additional damping behaviour in the martensite/austenite transformation temperature region can just be observed for composites with a matrix stiffness close to that of the Ni-Mn-Ga particles. If the matrix is too rigid, the particles are constrained without possibility to deform and if the matrix is too flexible, the matrix yields around the particles, so that nearly no stress is transferred from the matrix to the particles.

In all these references, the damping behaviour of one type of Ni-Mn-Ga composite is compared to that of reference composites and/or pure matrix materials either at room temperature or as a function of temperature, for a given solicitation. No information is however found about the frequency and strain amplitude dependency of the damping behaviour of Ni-Mn-Ga composites. While the twinning process in MSMAs is fast, the polymer matrix may exhibit time and rate dependent mechanical properties, which also contribute to the damping behaviour of MSMA composites. 
In this work, Ni-Mn-Ga powders with a 10M (pseudo-tetragonal martensitic), NM (nonmodulated tetragonal martensitic) or A (austenitic) crystal structure at room temperature were investigated for their transformation and Curie temperatures. In addition, the thermal characteristics of the epoxy system used as matrix material and cured at room or elevated temperature were analysed. Finally, powder composites were produced by casting and their temperature, strain amplitude and frequency dependent damping behaviour was analysed with dynamic mechanical analysis experiments.

\section{Materials and experimental techniques}

Different Ni-Mn-Ga powders were obtained by crushing ingots cast in the group of Prof. Müllner at Boise State University, USA, with both hammer and mortar. To guarantee a homogeneous particle size, the crushed powder was sieved after the crushing. As reference powders, Ni-Mn-Ga powder of low purity and non-MSMA Cu-Ni powder were used. The ingot composition, crystal structure and maximum particle size obtained after sieving of all powders are summarised in table 1. Since in polycrystalline Ni-Mn-Ga, strains of different grains are neutralised and/or hindered mutually, the Ni-Mn-Ga powders were annealed to stimulate grain growth and to release internal stresses caused by the crushing operation. The $10 \mathrm{M}-\mathrm{Ni}-\mathrm{Mn}-\mathrm{Ga}-180$ powder was annealed in a quartz ship covered with a piece of $\mathrm{Mn}$ and a Ti mesh under argon in a tube furnace for $3 \mathrm{~h}$ at $1000^{\circ} \mathrm{C}$. The Ni-Mn-Ga powders with a maximum particle size of $63 \mu \mathrm{m}$ were annealed at $1000^{\circ} \mathrm{C}$ for $1 \mathrm{~h}$ in a sealed, evacuated and argon backfilled quartz tube, containing $\mathrm{Mn}$ and $\mathrm{Zr}$. Ti and $\mathrm{Zr}$ served as oxygen getter; $\mathrm{Mn}$ was added to create a Mn atmosphere and prevent loss of Mn via evaporation.

Table 1. Ingot composition, crystal structure at room temperature (RT) and maximum particle size after sieving of all powders.

\begin{tabular}{llll}
\hline Powder name & Ingot composition & Crystal structure at RT & Max. particle size \\
\hline 10M-Ni-Mn-Ga-180 & $\mathrm{Ni}_{50.0 \pm 0.61} \mathrm{Mn}_{28.6 \pm 0.35} \mathrm{Ga}_{21.4 \pm 0.26}$ & $10 \mathrm{M}$ & $180 \mu \mathrm{m}$ \\
10M-Ni-Mn-Ga-63 & $\mathrm{Ni}_{51.2 \pm 0.01} \mathrm{Mn}_{26.6 \pm 0.01} \mathrm{Ga}_{22.2 \pm 0.01}$ & $10 \mathrm{M}$ & $63 \mu \mathrm{m}$ \\
NM-Ni-Mn-Ga-63 & $\mathrm{Ni}_{52.5 \pm 0.01} \mathrm{Mn}_{26.0 \pm 0.01} \mathrm{Ga}_{21.5 \pm 0.01}$ & $\mathrm{NM}$ & $63 \mu \mathrm{m}$ \\
A-Ni-Mn-Ga-63 & $\mathrm{Ni}_{49.9 \pm 0.01} \mathrm{Mn}_{26.8 \pm 0.01} \mathrm{Ga}_{23.3 \pm 0.01}$ & $\mathrm{~A}$ & $63 \mu \mathrm{m}$ \\
Ni-Mn-Ga-180 & $\mathrm{Ni}_{51.1 \pm 5.7} \mathrm{Mn}_{27.5 \pm 3.1} \mathrm{Ga}_{21.4 \pm 2.4}$ & unknown & $180 \mu \mathrm{m}$ \\
$\mathrm{Cu}-\mathrm{Ni}-180$ & $\mathrm{Cu}-\mathrm{Ni}$ & - & $180 \mu \mathrm{m}$ \\
\hline
\end{tabular}

As matrix material, the standard epoxy system Araldite LY 3297/ Aradur 3298 from Huntsman, USA, with a mix ratio of 100:40 by weight and a Young's modulus of about $3 \mathrm{GPa}$ at room temperature, was chosen.

Composites were prepared by mixing the powder with liquid epoxy in a silicon mould and degasing the mixture for $30 \mathrm{~min}$ in the mould. The composites for the temperature dependent damping measurements were prepared with the annealed 10M-Ni-Mn-Ga-180 powder as well as the 
reference powders $\mathrm{Ni}-\mathrm{Mn}-\mathrm{Ga}-180$ and $\mathrm{Cu}-\mathrm{Ni}-180$ as reinforcement phase, and were cured in the oven at $80{ }^{\circ} \mathrm{C}$ for $9 \mathrm{~h}$. The composites for the strain, frequency and Ni-Mn-Ga crystal structure dependent damping measurements, on the other hand, were prepared with the annealed $10 \mathrm{M}-\mathrm{Ni}$ Mn-Ga-63, NM-Ni-Mn-Ga-63 and A-Ni-Mn-Ga-63 powder as reinforcement phase. They were left alone for $40 \mathrm{~min}$ at room temperature after degassing to allow the powder to sediment on the bottom of the silicon mould before they were placed in a homogenous field of $1 \mathrm{~T}$, generated by an electromagnet, along the long sample axis to orient the Ni-Mn-Ga particles. After curing the mixtures for $170 \mathrm{~min}$ in the magnetic field, the epoxy was viscous enough to prevent any reorientation of the particles so that the magnetic field could be removed. To cure the epoxy without transforming the Ni-Mn-Ga particles to austenite, the samples were cured at room temperature for 3 weeks. Due to sedimentation of the powder on the bottom of the silicon mould, all cured composite samples were ground down to obtain samples with a homogeneous powder volume fraction. The resulting samples had a powder content of about $40 \mathrm{vol} . \%$ and $30 \mathrm{vol} . \%$ for the $180 \mu \mathrm{m}$ and the $63 \mu \mathrm{m}$ powder composites, respectively. The powder volume fraction was determined by measuring the weight and dimensions of the final samples, knowing the density of the powder and of the cured epoxy. As a reference sample, pure epoxy was also cast in silicon moulds, cured like the composite specimens and ground down to obtain about the same height as the composite specimens. The final sample dimensions were $35 \times 13 \times 0.5 \mathrm{~mm}^{3}$ for the temperature dependent damping measurements and $33 \times 5 \times 1 \mathrm{~mm}^{3}$ for the strain, frequency and Ni-Mn-Ga crystal structure dependent damping measurements.

To determine the grain size of the as-crushed and annealed Ni-Mn-Ga powder, cross sections of Ni-Mn-Ga particles embedded in an epoxy mounting medium were prepared, etched with an etching solution (99 $\mathrm{ml}$ ethanol, $5 \mathrm{~g}$ ferric chloride, $2 \mathrm{ml}$ nitric acid) and observed under an optical microscope. In addition, the morphology and quality of the powder composites were observed by optical microscopy of polished cross-sections. The transformation temperatures and glass transition temperature (determined from the midpoint of the step in the heat flow curve), respectively, of all as-crushed and annealed Ni-Mn-Ga powders, of the epoxy cured at room and elevated temperature as well as of the powder composites were detected by performing differential scanning calorimetry (DSC) tests. For all tests, a DSC Q100 from TA Instruments was used with a heating/cooling rate of $5{ }^{\circ} \mathrm{C} / \mathrm{min}$. The glass transition temperature of the pure epoxy was in addition determined by performing temperature dependent dynamic mechanical analysis (DMA) experiments. In this case, the glass transition temperature was determined from the onset point of the $\tan \delta$ peak. These tests were conducted on a DMA Q800 from TA Instruments, USA, using the single cantilever mode with a gauge length of $17.5 \mathrm{~mm}$. The heating rate was set to $5{ }^{\circ} \mathrm{C} / \mathrm{min}$. To investigate the damping behaviour of the Ni-Mn-Ga powder-epoxy matrix composites, DMA experiments were carried out using the same DMA Q800 from TA Instruments, USA, in the single cantilever mode with a gauge length of $17.5 \mathrm{~mm}$. The temperature dependency was measured from 0 to $120^{\circ} \mathrm{C}$ with a heating rate of $5{ }^{\circ} \mathrm{C} / \mathrm{min}$ at constant maximum strain amplitude of $0.5 \%$ and frequency of $1 \mathrm{~Hz}$. The strain dependency was investigated up to a maximum strain amplitude of $0.9 \%$ at constant frequency of $1 \mathrm{~Hz}$ and temperature of $21{ }^{\circ} \mathrm{C}$ and the frequency dependency from 0.1 to $15 \mathrm{~Hz}$ at constant maximum strain amplitude of $0.5 \%$ and temperature of $21^{\circ} \mathrm{C}$. 


\section{Results and discussion}

\subsection{Structural characterisation of powder and composites}

Figure 1 shows the etched cross sections of the as-crushed ((a) and (b)) and annealed ((c) and (d)) Ni-Mn-Ga powder 10M-Ni-Mn-Ga-180. All particles showed a polygonal shape caused by the crushing process. Furthermore, both particle types were single or nearly single crystals and exhibited twins. Thus, the heat treatment did not result in considerably larger grains but the particles were small enough to be almost all single crystals.
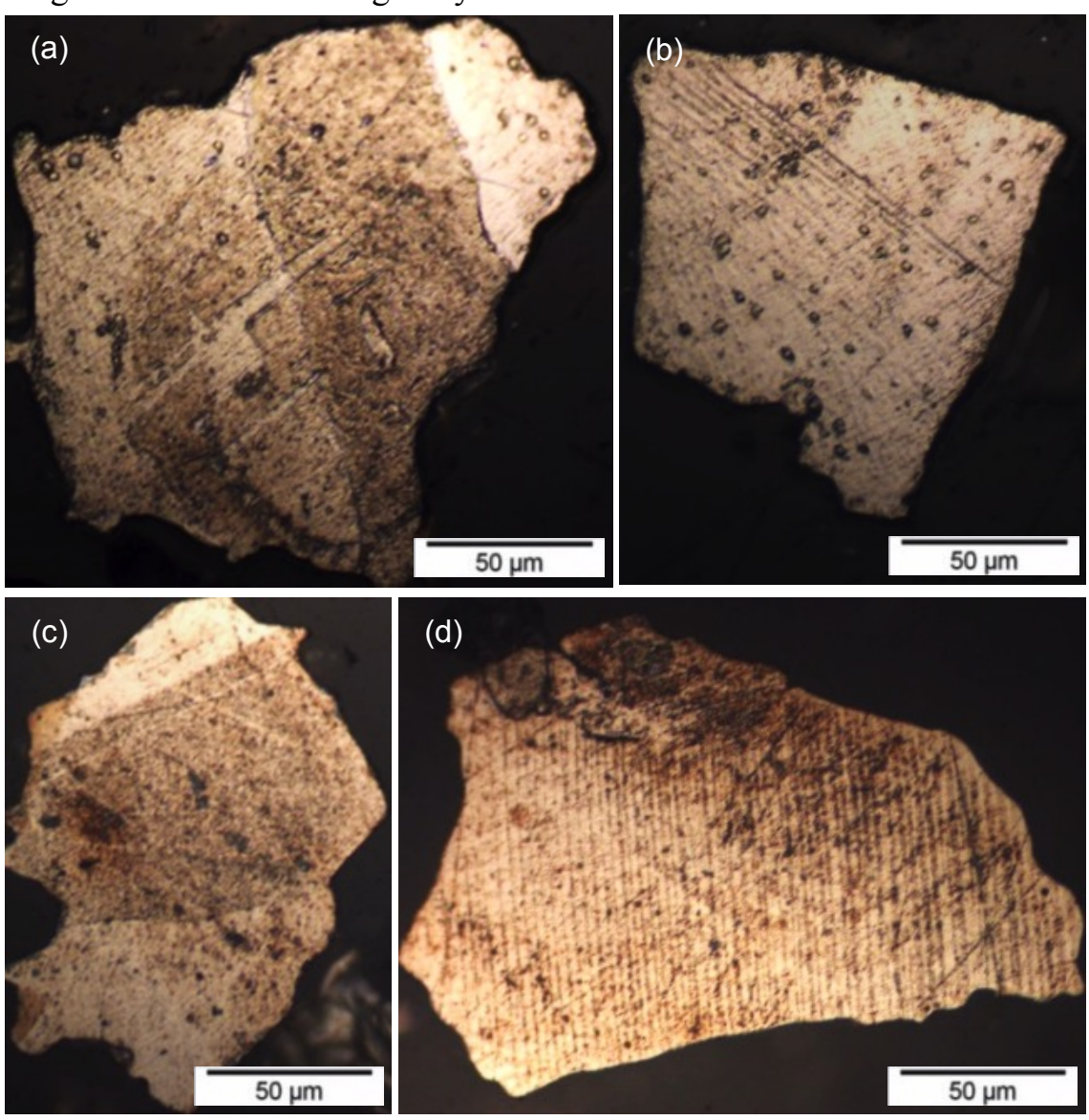

Figure 1. Etched cross sections of the as-crushed ((a) and (b)) and annealed ((c) and (d)) Ni-MnGa-180 particles. Both types have a polygonal shape, are single or nearly single crystals and exhibit twins.

Figure 2 shows a micrograph of the cross section of a $10 \mathrm{M}-\mathrm{Ni}-\mathrm{Mn}-\mathrm{Ga}-180$ powder-epoxy matrix composite. The particles were densely packed and homogeneously distributed, due to sedimentation during cure. No pores were observed. Thus, the degasing of the powder-epoxy mixture in the mould was successful and allowed manufacturing of good quality samples. 


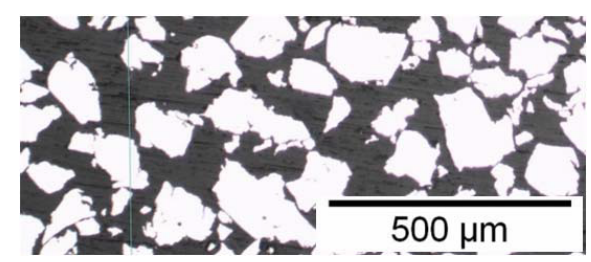

Figure 2. Micrograph of the cross-section of a 10M-Ni-Mn-Ga-180 powder-epoxy matrix composite.

\subsection{Thermal properties of powder, matrix and composites}

The DSC curves and corresponding transformation temperatures of all $\mathrm{Ni}-\mathrm{Mn}$-Ga powders are shown in figure 3 and table 2, respectively. All as-crushed powders did not show a clear martensitic and reverse martensitic transformation. This indicates that the crushing process induced internal stresses in the particles that inhibit and/or broaden the transformation. The DSC curves of the annealed powders, however, showed clear peaks for the martensitic and reverse martensitic transformation as well as a step at the Curie temperature, indicating that annealing of the powders caused a reduction of the internal stresses.
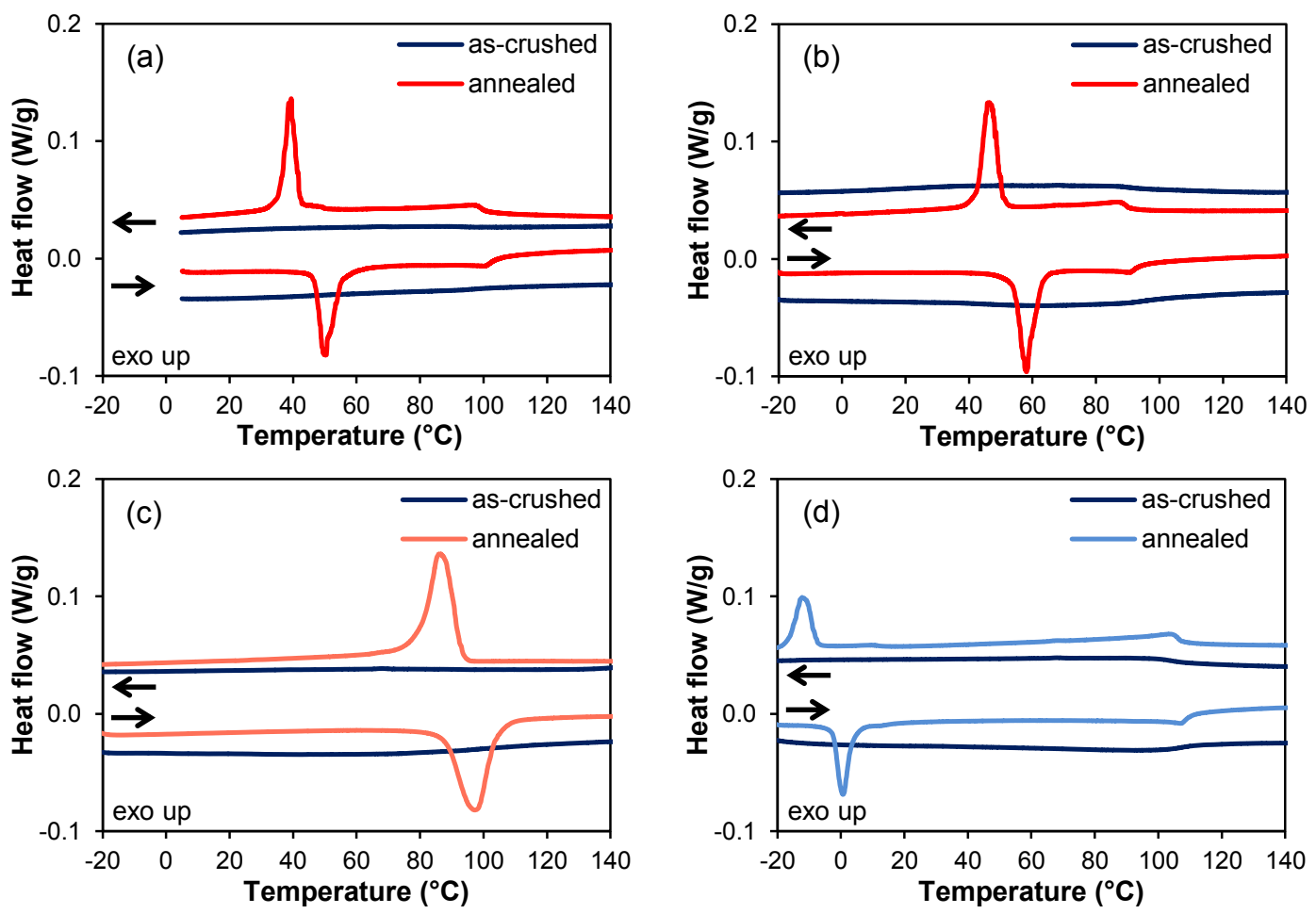

Figure 3. DSC curves of the as-crushed and annealed Ni-Mn-Ga powders. (a) 10M-Ni-Mn-Ga-180, (b) 10M-Ni-Mn-Ga-63, (c) NM-Ni-Mn-Ga-63, (d) A-Ni-Mn-Ga-63. 
Table 2. Transformation temperatures of all annealed Ni-Mn-Ga powders ( $A_{\mathrm{s}}$ and $A_{\mathrm{f}}$ : austenite start and finish temperature, $M_{\mathrm{s}}$ and $M_{\mathrm{f}}$ : martensitic start and finish temperature, $T_{\mathrm{c}}$ : Curie temperature).

\begin{tabular}{llllll}
\hline Powder & $A_{\mathrm{s}}\left({ }^{\circ} \mathrm{C}\right)$ & $A_{\mathrm{f}}\left({ }^{\circ} \mathrm{C}\right)$ & $M_{\mathrm{s}}\left({ }^{\circ} \mathrm{C}\right)$ & $M_{\mathrm{f}}\left({ }^{\circ} \mathrm{C}\right)$ & $T_{\mathrm{c}}\left({ }^{\circ} \mathrm{C}\right)$ \\
\hline 10M-Ni-Mn-Ga-180 & 46 & 56 & 43 & 35 & 104 \\
10M-Ni-Mn-Ga-63 & 54 & 63 & 51 & 42 & 93 \\
NM-Ni-Mn-Ga-63 & 87 & 104 & 93 & 79 & - \\
A-Ni-Mn-Ga-63 & -3 & 4 & -7 & -17 & 110 \\
\hline
\end{tabular}

Figure 4 presents the DSC curves of the epoxy system Araldite LY 3297/Aradur 3298 cured for $9 \mathrm{~h}$ at $80{ }^{\circ} \mathrm{C}$ or for 21 days at room temperature, respectively. The corresponding glass transition temperatures, $T_{\mathrm{g}}$, obtained from the first and the second heating curve are summarised in table 3 . For the sample cured at elevated temperature, $T_{\mathrm{g}}$ was slightly higher in the second heating cycle but no exothermal peak could be observed. The sample cured at room temperature, on the other hand, showed no clear glass transition in the first heating cycle, but a broad exothermal peak instead. The absence of an exothermal peak in the first heating curve of the epoxy system cured at elevated temperature indicates that the corresponding curing cycle was sufficient to fully cure the epoxy system. However, to fully cure this epoxy system, room temperature is not sufficient. The small difference in $T_{\mathrm{g}}$ between the first and second heat cycle might be caused by absorbed moisture in the epoxy that evaporated during the first heating cycle. Moisture results in resin plasticisation and thus reduces $T_{\mathrm{g}}$ [12]. Furthermore, both samples exhibited an endothermic peak in the first heating cycle at about $51 / 63{ }^{\circ} \mathrm{C}$ (for materials cured at room temperature/ $80{ }^{\circ} \mathrm{C}$ respectively). This peak, large or small for the sample cured at room temperature or at $80{ }^{\circ} \mathrm{C}$, respectively, is attributed to physical aging of the cured epoxy [117].

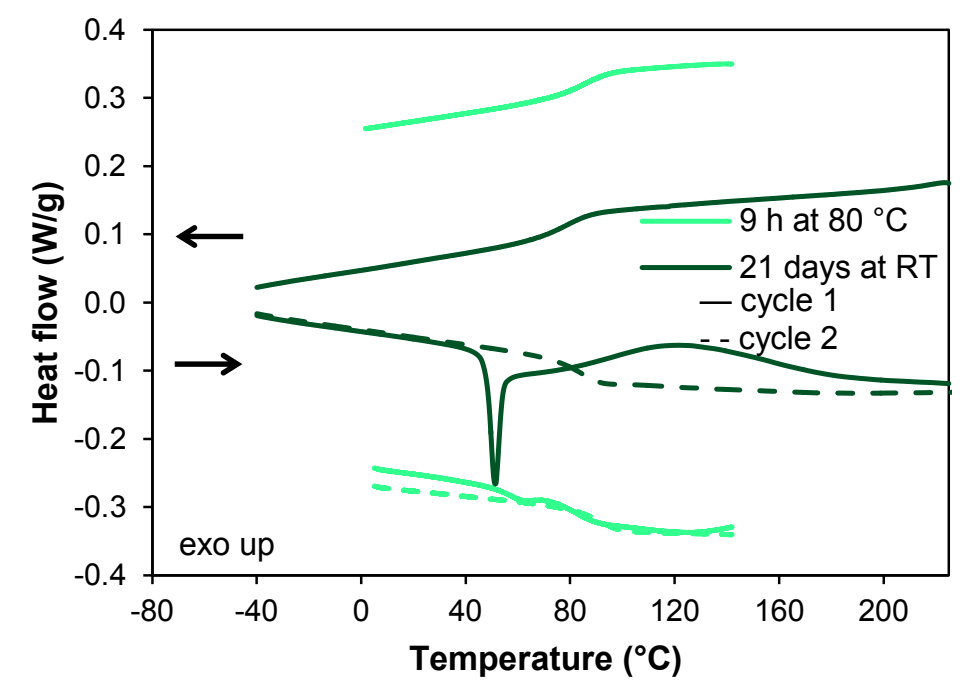

Figure 4. DSC curves of the pure epoxy cured at elevated and at room temperature. 
Table 3. Glass transition temperatures determined from the first and second heating cycle of the three different epoxy systems cured at elevated and at room temperature (RT).

\begin{tabular}{lll}
\hline Curing conditions & $T_{\mathrm{g}}$, cycle $1\left({ }^{\circ} \mathrm{C}\right)$ & $T_{\mathrm{g}}$, cycle $2\left({ }^{\circ} \mathrm{C}\right)$ \\
\hline $9 \mathrm{~h}$ at $80{ }^{\circ} \mathrm{C}$ & 80 & 90 \\
21 days at RT & $\approx 50$ & 84 \\
\hline
\end{tabular}

The results of the DMA tests performed on the epoxy system Araldite LY 3297/Aradur 3298 cured for $9 \mathrm{~h}$ at $80{ }^{\circ} \mathrm{C}$ or for 21 days at room temperature, respectively, are shown in figure 5 . Loss modulus and loss ratio (tan $\delta$ ) showed a strong increase at about $90{ }^{\circ} \mathrm{C}$ and $55{ }^{\circ} \mathrm{C}$ for the epoxy sample cured at elevated and room temperature, respectively, resulting in a peak. These temperatures can be related to the glass transition of the epoxy. Below those temperatures, both loss modulus and loss ratio were almost identical for both curing cycles and increased only slightly with increasing temperature.

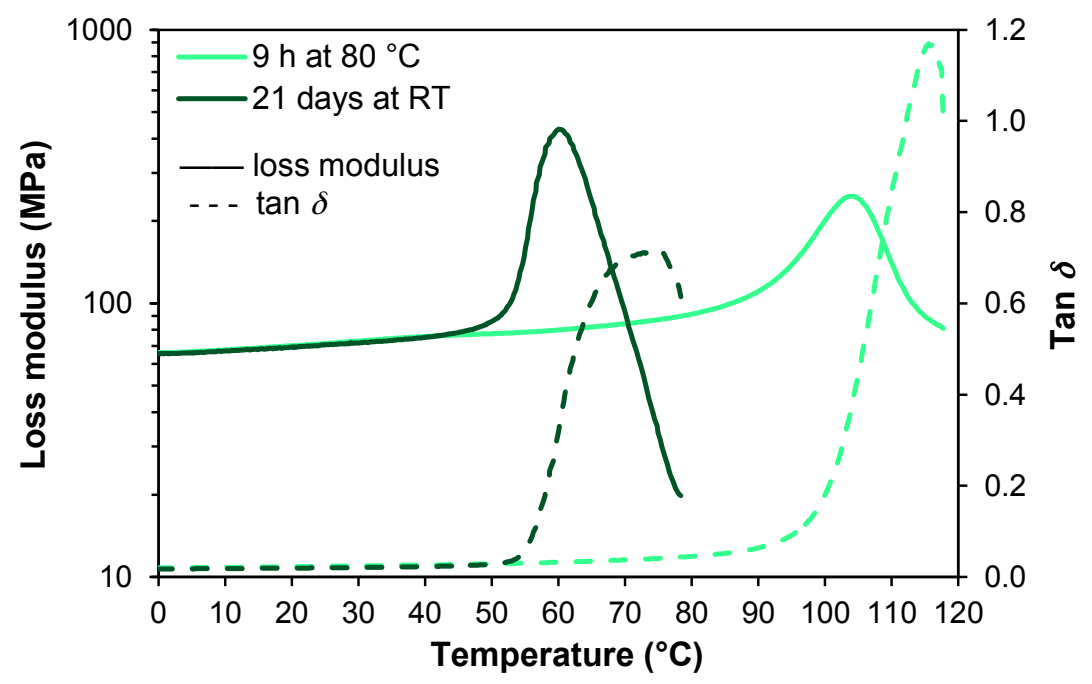

Figure 5. Loss modulus and loss ratio $(\tan \delta)$ as a function of temperature for the pure epoxy cured at elevated and room temperature.

Figure 6 respectively presents the DSC curves of (a) a 10M-Ni-Mn-Ga-180 powder composite cured at room temperature and (b) the three Ni-Mn-Ga-63 powder composites cured at $80{ }^{\circ} \mathrm{C}$. For all composites, the martensite/austenite transformation and the Curie temperature corresponded well to the temperatures observed for the pure Ni-Mn-Ga powders. In addition, the endothermic aging peaks of the composites cured at room temperature were consistent with the peak of the pure epoxy system. Only the glass transition and the small aging peak of the composites cured at $80{ }^{\circ} \mathrm{C}$ could not be detected due to an overlap with the martensite/austenite transformation and Curie temperature and because the epoxy mass fraction was low. Thus, the observed thermal behaviour of the Ni-Mn-Ga composites is the superposition of the thermal behaviour of the Ni-Mn-Ga powder 
and of the epoxy and the chosen epoxy system does not affect or hinder the martensite/austenite transformation in the powders.
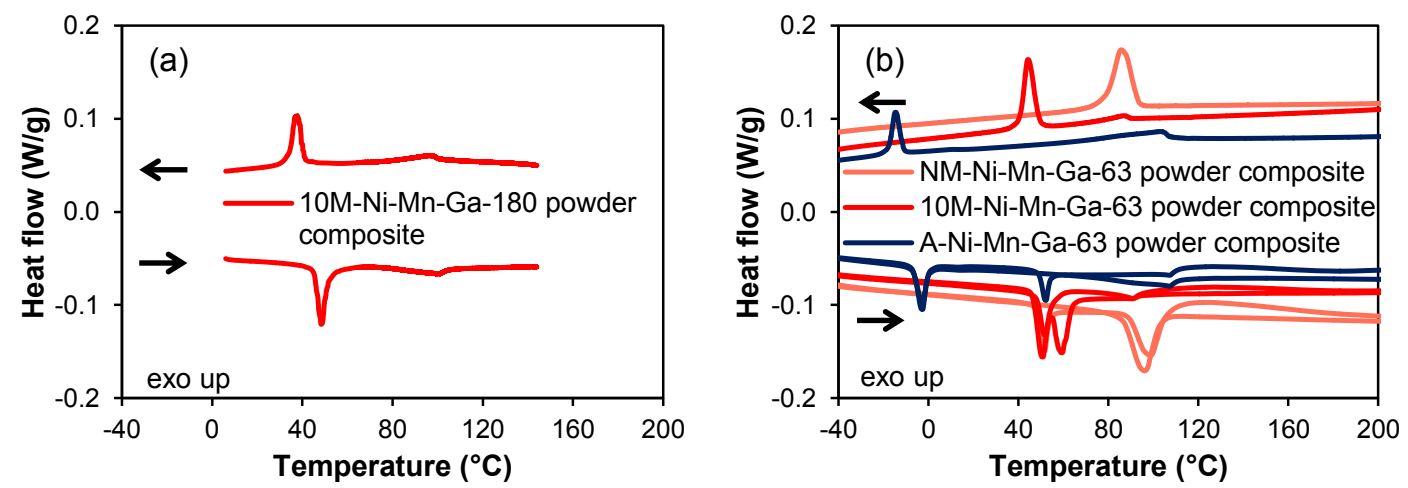

Figure 6. DSC curves of a 10M-Ni-Mn-Ga-180 powder composite cured at room temperature (a) and the three Ni-Mn-Ga-63 powder composites cured at $80{ }^{\circ} \mathrm{C}$ (b).

\subsection{Damping behaviour}

3.3.1. Effect of temperature. The temperature dependent DMA test results with a heating rate of $5{ }^{\circ} \mathrm{C} / \mathrm{min}$ for one $10 \mathrm{M}-\mathrm{Ni}-\mathrm{Mn}-\mathrm{Ga}-180$ powder-epoxy matrix composite, one low purity Ni-Mn-Ga180 powder-epoxy matrix composite, one $\mathrm{Cu}-\mathrm{Ni}$ powder-epoxy matrix composite and one pure epoxy sample all cured at $80{ }^{\circ} \mathrm{C}$, are illustrated in figure 7 . For each type of material, four different samples were tested. The scatter of the values for the different samples is, however, for the sake of clarity, only shown as points at room temperature. All samples exhibited a clear decrease of the storage modulus and an increase of the loss ratio at around 95 to $98{ }^{\circ} \mathrm{C}$ resulting in a peak at about $115^{\circ} \mathrm{C}$. This refers, according to the DSC measurement on the pure epoxy cured at $80{ }^{\circ} \mathrm{C}$ for $9 \mathrm{~h}$, to the glass transition of the epoxy matrix. The 10M-Ni-Mn-Ga-180 composite showed another smaller $\tan \delta$ peak at around $60^{\circ} \mathrm{C}$ combined with an increase of the storage modulus. This increased damping behaviour and change of the storage modulus originates, according to the DSC measurement on the $10 \mathrm{M}-\mathrm{Ni}-\mathrm{Mn}-\mathrm{Ga}-180$ powder, from the crystallographic martensite/austenite transformation that does not exist in the $\mathrm{Cu}-\mathrm{Ni}$ powder and is inhibited in the as-crushed low purity Ni-Mn-Ga-180 powder. Similar results were observed by Sun at al. [7] for Ni-Mn-Ga powderepoxy matrix composites.

The comparison of the curves below the martensitic transformation shows that the storage modulus of all composite types was, due to the reinforcing effect of the powder, higher than the modulus of the pure epoxy. The loss ratio was with $0.025 \pm 0.002$ (at room temperature) lowest for the epoxy sample. All composites showed an increased loss ratio, which is generally attributed to the dissipative effects of the powder-matrix interface. Regarding the three composite types, the loss ratio of the 10M-Ni-Mn-Ga-180 powder composite was with $0.064 \pm 0.002$ (at room temperature) about 1.6 times higher than that of the $\mathrm{Cu}-\mathrm{Ni}-180$ composite and about 1.9 times higher than that the low purity Ni-Mn-Ga-180 powder composite. According to this result, since interface properties are similar to those of the low purity Ni-Mn-Ga composite, the ferromagnetic Ni-Mn-Ga powder 
with $10 \mathrm{M}$ structure shows additional dissipative processes including twinning or intermartensitic transformations of the particles that do not take place in the two reference powders. These results are in agreement with those reported by Feuchtwanger et al. [5, 13] and Lahelin et al. [8]. Furthermore, the loss ratio of the $\mathrm{Cu}-\mathrm{Ni}-180$ powder composite was at $0.041 \pm 0.003$ (at room temperature) higher than the loss ratio of the low purity Ni-Mn-Ga-180 powder composite at 0.034 \pm 0.001 (at room temperature). This difference in the dissipative properties can be attributed to several causes: the interface quality of the $\mathrm{Cu}-\mathrm{Ni}$ particle/epoxy interface may be worse than that of the Ni-Mn-Ga particle/epoxy interface and/or the ductile $\mathrm{Cu}-\mathrm{Ni}$ particles exhibit a higher plastic deformation than the brittle Ni-Mn-Ga particles.

Regarding the loss ratio of the $10 \mathrm{M}-\mathrm{Ni}-\mathrm{Mn}-\mathrm{Ga}-180$ powder composite below and above the martensitic transformation (but below $T_{\mathrm{g}}$ ), a higher $\tan \delta$ was found in the martensitic phase. In the austenitic phase, the loss ratio was similar to that of the low purity Ni-Mn-Ga-180 powder composite. This confirms that the 10M-Ni-Mn-Ga-180 powder composite exhibits, beside the dissipative effect of the particle/epoxy interface an additional dissipative effect in the martensitic phase of the powder. Considering that the low purity composite does not show any dissipative effects characteristic of ferromagnetic shape memory alloys, the 10M-Ni-Mn-Ga-180 powder composite does not show them either above the transformation temperature. Thus, we can conclude that no stress induced martensitic transformation occurs in the austenitic phase during the damping test at low strains, and all additional damping effects occur only below the martensitic transformation. 

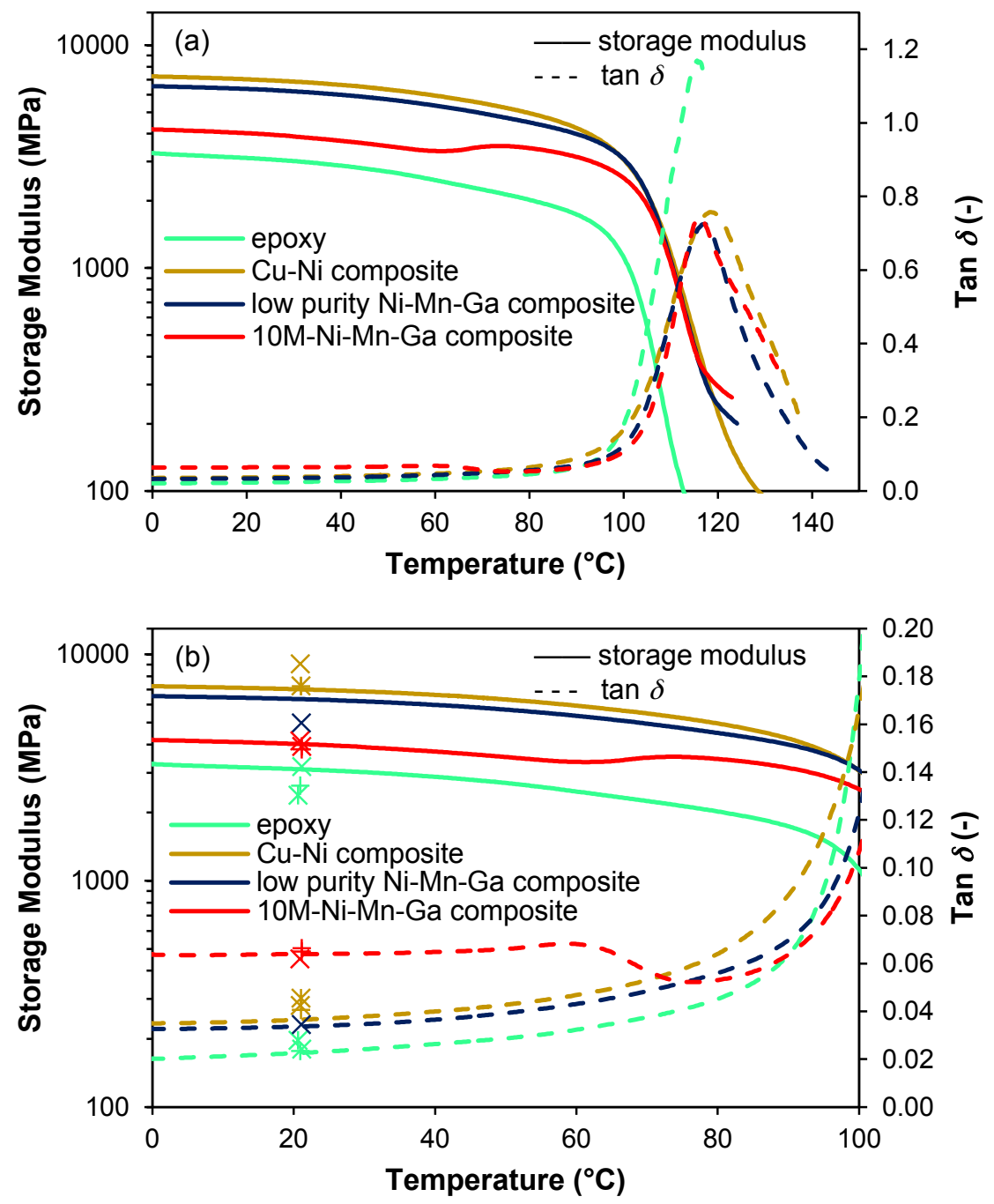

Figure 7. Storage modulus and loss ratio $(\tan \delta)$ as a function of temperature $\left(0\right.$ to $150{ }^{\circ} \mathrm{C}$ in (a) and 0 to $100{ }^{\circ} \mathrm{C}$ enlarged in (b)) for a pure epoxy sample, a $\mathrm{Cu}-\mathrm{Ni}$ composite, a reference low purity NiMn-Ga composite and a $10 \mathrm{M}-\mathrm{Ni}-\mathrm{Mn}-\mathrm{Ga}$ composite cured all at $80^{\circ} \mathrm{C}$ as well as data scatter for the different samples of the same type at room temperature.

3.3.2. Effect of frequency and strain at room temperature. The results of the frequency dependent damping measurements of the Ni-Mn-Ga-63 powder composites and the pure matrix cured at room temperature, as well as the scatter of the values for the different samples, shown as points at $1 \mathrm{~Hz}$, are illustrated in figure 8. The strain amplitude dependent damping measurements and the scatter of the values for the different samples, shown as points at strain amplitude of $0.49 \%$, are illustrated in figure 9. For each type of material, three different samples were tested. Note that the A-Ni-Mn-Ga powder composites broke at about $1 \mathrm{~Hz}$ and at a strain amplitude of $0.6 \%$ so that no data for higher frequencies and strain amplitudes could be measured for that material. 


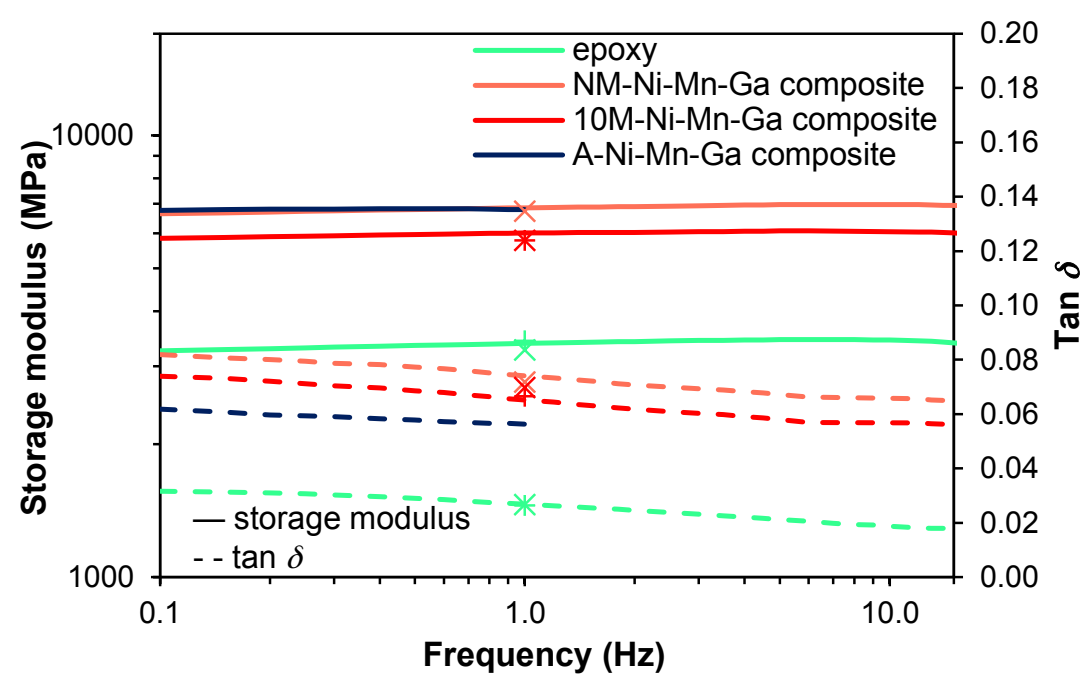

Figure 8. Storage modulus and loss ratio $(\tan \delta)$ as a function of frequency for a pure epoxy sample and the Ni-Mn-Ga-63 composites cured all at room temperature as well as data scatter for the different samples of the same type at $1 \mathrm{~Hz}$.

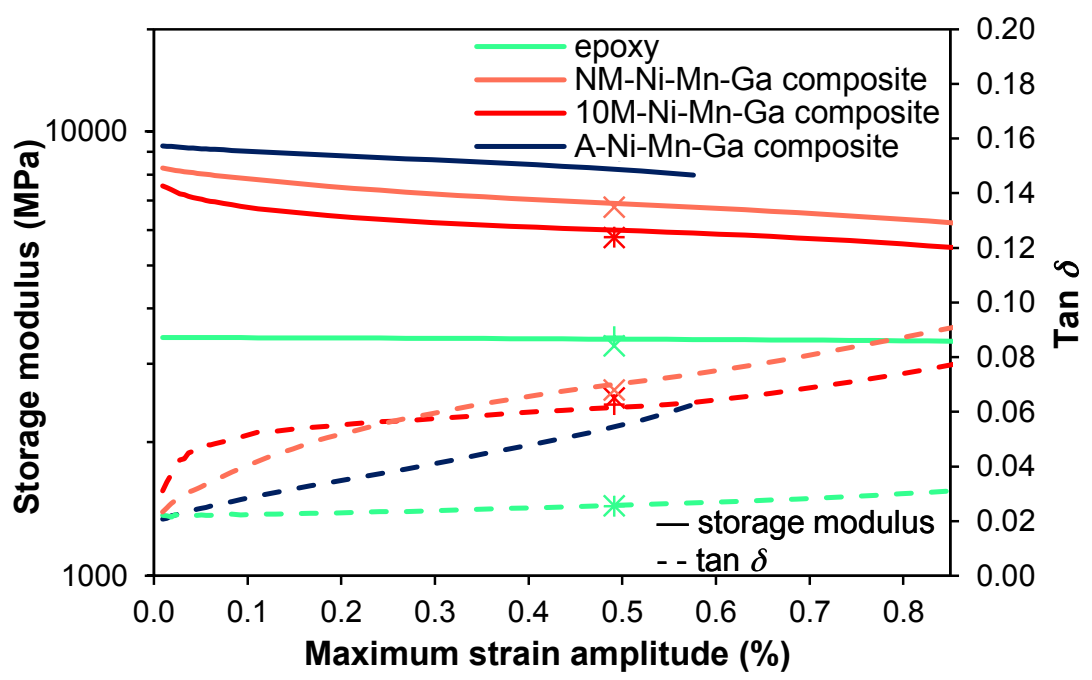

Figure 9. Storage modulus and loss ratio $(\tan \delta)$ as a function of maximum strain amplitude for a pure epoxy sample and the Ni-Mn-Ga-63 composites cured all at room temperature as well as data scatter for the different samples of the same type at maximum strain amplitude of $0.49 \%$.

All samples showed an increasing storage modulus and decreasing loss ratio with frequency. This can be related to the viscoelastic behaviour of the epoxy matrix. Since the maximum strain amplitude was kept constant, increasing frequency is equivalent to increasing strain rate, thereby increasing the matrix storage modulus.

With increasing strain amplitude, the storage modulus of the epoxy decreased only marginally (by about $1.5 \%$ between 0.1 and $0.8 \%$ strain), the modulus of all composite samples, however, considerably (by about $19 \%$ between 0.1 and $0.8 \%$ strain). The loss ratio, on the other 
hand, increased with increasing strain amplitude for all samples, but again considerably more for the composite samples. This behaviour implies that the viscoelastic behaviour of the matrix as well as dissipative effects of the matrix/powder interface are more pronounced with increasing strain. Furthermore, the increase was not linear, but showed a stronger strain dependency for strain amplitudes larger than about $0.6 \%$. This indicates that for strain amplitudes larger than $0.6 \%$, the epoxy system shows a slightly enhanced plastic deformation which might as well have an influence on the quality of the matrix/particle interface. In addition, the 10M- and NM-Ni-Mn-Ga powder composites exhibited a stronger dependency for strain amplitudes below about $0.04 \%$ and $0.15 \%$, respectively. Since the A-Ni-Mn-Ga powder composite did not show such an enhanced dependency for small strain amplitudes, this behaviour might be related to the fact that twin boundary motion, taking place only in the martensitic powders, requires overcoming of a threshold activation stress. Since the twinning stress in NM Ni-Mn-Ga is generally higher than that in $10 \mathrm{M} \mathrm{Ni-Mn-Ga}[3,14]$, larger strains are necessary to fully activate the twinning in the NM powder. Such behaviour was also reported by other researchers for Ni-Mn-Ga single crystals $[15,16]$.

Regarding the qualitative order of the loss ratio for the frequency and strain amplitude dependent measurements, all composite samples exhibited a higher $\tan \delta$ than the pure epoxy sample. This indicates that the matrix/particle interface causes, as for the Ni-Mn-Ga-180 powder composites, a dissipative effect. Furthermore, the frequency dependent loss ratio of the NM-Ni-MnGa powder composite was about $12 \%$ higher than that of the $10 \mathrm{M}-\mathrm{Ni}-\mathrm{Mn}-\mathrm{Ga}$ powder composite and $24 \%$ higher than that of the A-Ni-Mn-Ga powder composite. Thus, NM- and 10M-Ni-Mn-Ga powder composites exhibit an additional damping effect that is not present in the A-Ni-Mn-Ga powder composite. Since in the austenitic phase no twins exist and the powder is brittle, stress induced twinning is probably the additional dissipative effect in the two martensitic powders. Furthermore, due to the fact that the twinning stress in NM martensite, as mentioned above, is generally higher than in $10 \mathrm{M}$ martensite, twin boundary motion dissipates more energy in the NM powder. For strain amplitudes below about $0.25 \%$ however, $\tan \delta$ of the $10 \mathrm{M}-\mathrm{Ni}-\mathrm{Mn}-\mathrm{Ga}$ powder composite was larger than that of the NM-Ni-Mn-Ga powder composite since twinning is activated to a larger extent in the $10 \mathrm{M}$ powder.

The comparison of the storage moduli for all samples shows that all composites exhibited higher moduli than the pure epoxy sample, due to the reinforcement effect of the powder. Within the different composite samples, the A-Ni-Mn-Ga composites exhibited the highest storage modulus. This could be related to reduction in apparent modulus caused by twinning as observed for the temperature dependent damping measurement on the Ni-Mn-Ga-180 powder composite shown in figure 7.

For applications requiring damping, the dissipated energy is a crucial parameter. The energy per unit volume dissipated during one loading/unloading cycle of a viscoelastic material is for the single cantilever mode given by (assuming that dissipated energy is counted as positive) [17]: 


$$
\Delta W=\frac{1}{9} \pi E^{\prime} \tan \delta \varepsilon_{0}^{2}
$$

The dissipated energy is proportional to the product of the loss ratio, $\tan \delta$, and the storage modulus, $E$, thus to the loss modulus of the sample ( $\varepsilon_{0}$ is the maximum strain amplitude imposed to the sample during one cycle and observed only at the sample surface at the edge of the fixed end). Note that Eq.(1) is rigorously valid for small strains, when the apparent modulus of the NiMnGa is not reduced and the material is linear viscoelastic. As shown in figure 10 (a), the dissipated energy decreases with increasing frequency for all samples. This can be explained by consideration of the temperature dependent damping measurements of the pure epoxy sample, figure 5. The epoxy exhibits its glass transition, indicated by a strong increase of the loss ratio and the loss modulus resulting in a peak, well above room temperature. Thus around room temperature, the loss modulus decreases with decreasing temperature. Knowing that a temperature decrease has the same effect on the damping behaviour as a frequency increase finally explains the frequency behaviour of dissipated energy of all samples.

Figure 10 (b) illustrates the dissipated energy for all samples as a function of $\varepsilon_{0}^{2}$. All samples show a linear increase, as expected from Eq. 1; the slope however suddenly increases for the composites at about 0.000036 corresponding to a strain amplitude of $0.6 \%$. This confirms that, for strain amplitudes larger than about $0.6 \%$, an additional damping effect is activated in all composite samples.

Regarding the order of all samples, the pure epoxy samples dissipated less energy than the composite samples due to their low storage modulus. Within the composite samples, the energy dissipated in the A-Ni-Mn-Ga powder composite was similar to the energy dissipated in the 10MNi-Mn-Ga powder composite, but about $30 \%$ smaller than the energy dissipated in the NM-Ni-MnGa powder composite. This illustrates the importance of the sample storage modulus on the dissipated energy. The extra damping effect of the twinning in the $10 \mathrm{M}$ powder is compensated by the significantly larger storage modulus of the A-Ni-Mn-Ga powder composite compared to the 10M-Ni-Mn-Ga powder composite. Thus, for applications requiring damping, a high loss ratio but also a high sample storage modulus are essential to guarantee a good damping behaviour. This makes MSMA fibres potentially relevant candidates to improve both loss ratio and storage modulus [9]. 

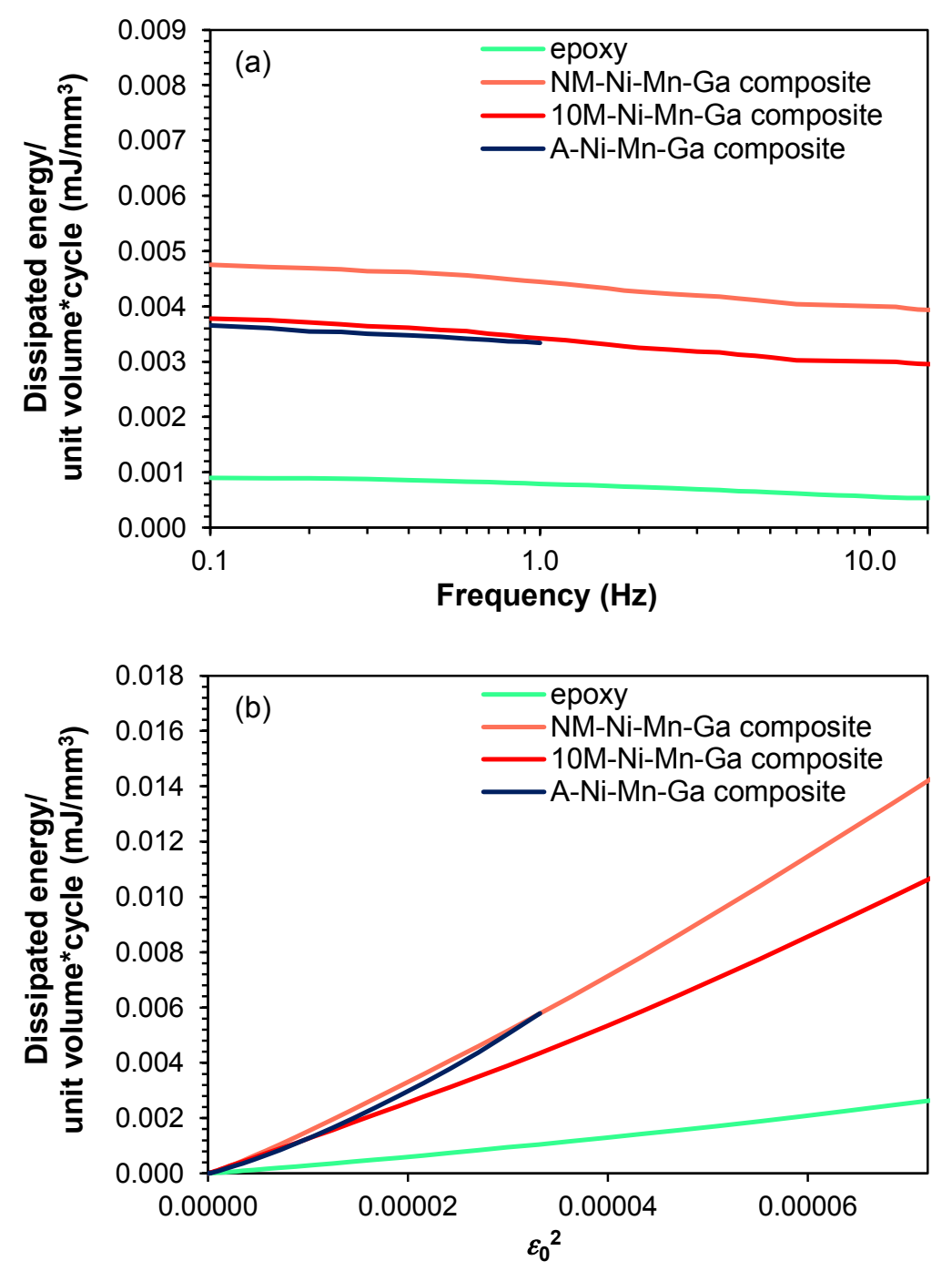

Figure 10. Dissipated energy per unit volume and cycle as a function of frequency (a) and $\varepsilon_{0}^{2}(\mathrm{~b})$ for all Ni-Mn-Ga-63 powder composites and pure epoxy samples cured at room temperature.

3.3.3. Stiffness-loss ratio map. Figure 11 shows the stiffness-loss ratio map for the Ni-Mn-Ga powder composite and matrix material tested in this work compared to Ni-Mn-Ga powder and fibreepoxy matrix composites found in literature as well as to other materials including rubber, traditional epoxy matrix composites with carbon or glass fibres, flax fibre reinforced epoxy matrix composites and bulk Ni-Mn-Ga. These materials have been chosen either because of their known use as dampers, or because they are known to be structural composites, as a comparison. Note however, that the loss ratio depends not only on the materials intrinsic damping mechanisms but also on the test conditions (e.g. temperature, frequency and maximum strain amplitude) and in case of composites on the interfacial properties as well. Since test conditions and interfacial properties are different for the materials compared here, the interpretation of the stiffness-loss ratio map needs to be taken with care. Nonetheless, Ni-Mn-Ga composites seem to have, in comparison to classical 
composites and damping materials, thanks to their high loss ratio combined with an intermediate stiffness a promising potential for damping applications.

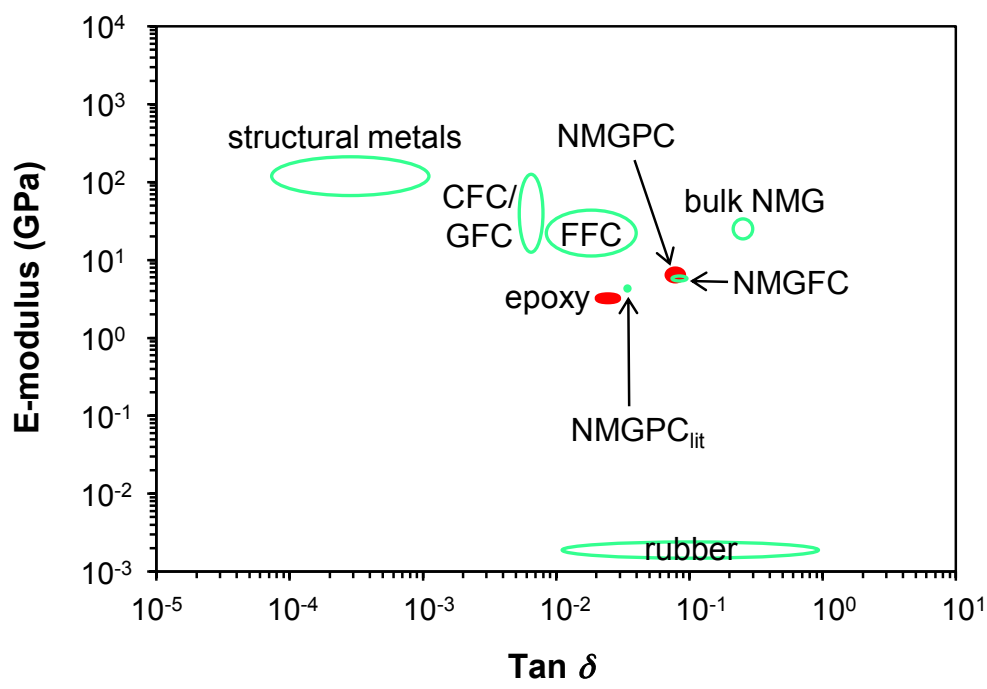

Figure 11. Stiffness-loss ratio map for the composite and matrix material tested in this work (filled) compared to other materials (not filled). (CFC/GFC: carbon/glass fibre-epoxy matrix composite and FFC: flax fibre-epoxy matrix composite after [18], bulk NMG: bulk Ni-Mn-Ga after [19], NMGPC $_{\text {lit }}$ : Ni-Mn-Ga powder-epoxy matrix composite after [7], NMGFC: Ni-Mn-Ga fibre-Araldite LY 3297/Aradur 3298 matrix composite after [9], rubber after [20, 21], structural metals after [20], epoxy: epoxy system Araldite LY 3297/Aradur 3298, NMGPC: Ni-Mn-Ga powder-Araldite LY 3297/Aradur 3298 matrix composite.)

\section{Conclusions}

Ni-Mn-Ga powder/epoxy composites were successfully produced by casting. The damping behaviour as a function of temperature revealed that the martensitic transformation in the Ni-Mn-Ga elements and the glass transition in the epoxy matrix resulted as expected in increased damping at the corresponding transition temperatures. Below both transformation temperatures, which correspond to the temperature range of interest for damping applications in epoxy composites, the annealed martensitic Ni-Mn-Ga powder composite showed an increased damping behaviour due to stress induced twin boundary motion in the Ni-Mn-Ga elements, compared to other reinforcements and to the pure matrix. Within the martensitic Ni-Mn-Ga powder composites, twinning produced a larger dissipative effect in the NM powder than in the $10 \mathrm{M}$ powder since its twinning stress is higher. Furthermore, the dissipative effects of the matrix/powder interface and the viscoelastic behaviour of the matrix were more pronounced with increasing strain amplitude and it was observed that a threshold stress level was needed to fully activate twinning. The viscoelastic behaviour of the matrix, on the other hand, resulted in a loss ratio decrease with increasing frequency or strain rate. Overall, the damping potential of these composites, compared to traditional load bearing composites, and to damping elastomers, shows an interesting combination of modulus and loss factor, which could be further improved by the use of Ni-Mn-Ga fibres rather than powders, or by 
the development of hybrid composites, combining ferromagnetic fibres with structural reinforcement fibres such as glass or carbon. The ease of manufacturing and shaping, the cost and density of these materials, as compared to bulk single crystal Ni-Mn-Ga is also greatly improved, bringing these materials closer to potential applications.

\section{Acknowledgement}

This work is supported by the Swiss National Science Foundation under the National Research Programme NRP 62 nº6 $^{\circ}$ 6240-126120. We would like to thank Prof. Peter Müllner, Nikki Kucza and Eric Rhoads from the Boise State University, Idaho, US, for preparing and characterising the Ni-Mn-Ga ingots, as well as for fruitful discussions, and Alberto Sicco from EPFL who took part in this work during his studies.

\section{References}

[1] Sozinov A, Likhachev AA, Lanska N and Ullakko K 2002 Giant magnetic-field-induced strain in NiMnGa seven-layered martensitic phase Appl. Phys. Lett. 80 1746-8

[2] Marioni MA, O'Handley RC and Allen SM 2003 Pulsed magnetic field-induced actuation of NiMn-Ga single crystals Appl. Phys. Lett. 83 3966-8

[3] Sozinov A, Likhachev AA and Ullakko K 2001 Magnetic and magnetomechanical properties of Ni-Mn-Ga alloys with easy axis and easy plane of magnetization Proc. SPIE: Smart Structures and Materials 2001: Active Materials: Behavior and Mechanics (Spie-Int Soc Optical Engineering vol 4333) pp 189-96

[4] Straka L, Lanska N, Ullakko K and Sozinov A 2010 Twin microstructure dependent mechanical response in Ni-Mn-Ga single crystals Appl. Phys. Lett. 96 131903(1)-(3)

[5] Feuchtwanger J, Michael S, Juang J, Bono D, O'Handley RC, Allen SM, Jenkins C, Goldie J and Berkowitz A 2003 Energy absorption in Ni-Mn-Ga-polymer composites J. Appl. Phys. 93 8528-30

[6] Gans E and Carman GP 2006 Cyclic actuation of Ni-Mn-Ga composites J. Appl. Phys. 99 084905(1)-(4)

[7] Sun XG and Xie CY 2007 Damping characteristics of a NiMnGa/polymer composite material Mater. Sci. Forum 561-565 697-9

[8] Lahelin M, Aaltio I, Heczko O, Soderberg O, Ge Y, Lofgren B, Hannula SP and Seppala J 2009 DMA testing of Ni-Mn-Ga/polymer composites Compos. Part. A, Appl. Sci. Manuf. $40125-$ 9

[9] Glock S, Zhang X, Kucza N, Müllner P and Michaud V 2014 Structural, physical and damping properties of melt-spun Ni-Mn-Ga wire-epoxy composites Compos. Part. A, Appl. Sci. Manuf. 63 68-75

[10] Feuchtwanger J, Aurrekoetxea J, Zurbitu J, Vilas JL, Leon LM, Barandiaran JM, Hosoda H and Chernenko VA 2014 Impact Damping in NiMnGa/Polymer Composites Mater. Trans. 55 629-32

[11] Liang W, Yu H, Yufeng L and Naibin Y 2013 Damping of Ni-Mn-Ga epoxy resin composites Chin. J. Aeronaut. 26 1596-605

[12] Kelley FN and Bueche F 1961 Viscosity and glass temperature relations for polymer-diluent systems J. Polym. Sci. 50 549-56

[13] Feuchtwanger J, Richard ML, Tang YJ, Berkowitz AE, O'Handley RC and Allen SM 2005 Large energy absorption in Ni-Mn-Ga/polymer composites J. Appl. Phys. 97 10M319(1)$10 \mathrm{M}(3)$ 
[14] Straka L, Hänninen H, Soroka A and Sozinov A 2011 Ni-Mn-Ga single crystals with very low twinning stress J. Phys.: Conf. Series 303 012079(1)-(10)

[15] Wang W, Liu G and Wu G 2006 Magnetically controlled high damping in ferromagnetic $\mathrm{Ni}_{52} \mathrm{Mn}_{24} \mathrm{Ga}_{24}$ single crystal Appl. Phys. Lett. 89 101911--3

[16] Aaltio I, Mohanchandra K, Heczko O, Lahelin M, Ge Y, Carman G, Söderberg O, Löfgren B, Seppälä J and Hannula S-P 2008 Temperature dependence of mechanical damping in NiMn-Ga austenite and non-modulated martensite Scripta Mater. 59 550-3

[17] Glock S 2014 Magnetic shape memory alloy composites, PhD thesis $n^{\circ} 6334$ (Lausanne: Ecole Polytechnique Fédérale de Lausanne)

[18] Duc F 2014 Damping phenomena in natural fibre composites PhD Thesis $n^{\circ} 6275$ (Lausanne: Ecole Polytechnique Fédérale Lausanne)

[19] Gans E 2007 Characterizing Ni-Mn-Ga bulk and composites for actuation and damping Phd Thesis (Los Angeles: University of California)

[20] Brodt M and Lakes R 1995 Composite materials which exhibit high stiffness and high viscoelastic damping J. Compos. Mater. 29 1823-33

[21] Soutrenon M and Michaud V 2012 Structural damping using encapsulated shear thickening fluids Proc. of SPIE: Active and Passive Smart Structures and Integraded Systems 2012 (International Society for Optics and Photonics vol 8341) pp 83410S-1-S-12 